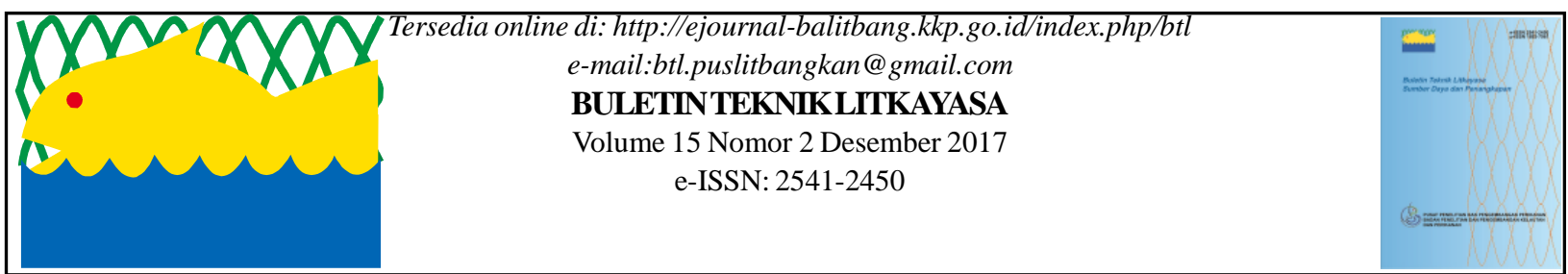

\title{
TEKNIK IDENTIFIKASI JENIS KELAMIN LOBSTER BERBASIS CIRI-CIRI MORFOLOGI
}

\author{
Sukamto, Tri Muryanto dan Hendra Kuslani \\ Teknisi Litkayasa Pada Balai Penelitian Pemulihan dan Konservasi Sumber Daya Ikan \\ Teregistrasi I tanggal: 30 November 2017; Diterima setelah perbaikan tanggal: 08 Desember 2017; \\ Disetujui terbit tanggal: 13 Desember 2017
}

\section{PENDAHULUAN}

Lobster merupakan salah satu komoditas perikanan andalan Indonesia karena mempunyai nilai ekonomis penting, baik untuk pasar dalam negeri maupun luar negeri. Saat ini kebutuhan akan lobster masih mengandalkan hasil tangkapan dari laut. Lobster laut sangat beragam jenisnya dan mempunyai spesifikasi perkembangan dan habitat hidup berbeda.

Di Indonesia telah dikenal enam jenis Lobster dan mempunyai spesifikasi perkembangan dan habitat hidup berbeda. tropical spiny lobster dari Famili Palinuridae, yaitu Lobster Pasir (Panulirus homarus), Lobster Mutiara ( $P$. ornatus), Lobster Batik ( $P$. longipes ), Lobster Bambu ( $P$. versicolor), Lobster Pakistan/Lumpur ( $P$. polyphagus ) dan Lobster Batu ( $P$. penicillatus) (Tewfik et al., 2009; Phillips, 2006). Jenis lain yang juga ditemukan di perairan Indonesia adalah $P$. daypus (Junaidi et al., 2010). Kelompok ini mudah dikenali karena bentuknya yang menarik, berwarna -warni dan lebih besar dibanding dengan jenis lainnya. Selain mempunyai bentuk tubuh yang lebih besar, kerangka kulit lobster lebih kaku, keras dan mempunyai zat kapur, sedang jenis crustacea lainnya khususnya udang, memiliki kulit lebih tipis, tembus cahaya dan terdiri dari zat kitin. Hampir seluruh tubuh lobster terdapat duri-duri besar maupun kecil yang kokoh dan tajam-tajam, mulai dari ujung sungut kedua (second antena), kepala, bagian belakang badan dan lembaran (Anonimus, 2016). Berdasarkan karateristik warna dan corak, mudah bagi kita untuk membedakan jenis lobster secara cepat sehingga dengan mudah dapat mengidentifikasi jenisnya.

Berdasarkan kondisi tersebut maka kelestarian dan produksi perlu ditingkatkan dengan pengelolaan pada asas keberkelanjutan dengan memberi kesempatan induk memijah, menjaga minimal induk di setiap area dan memperbaiki habitat. Tetapi hal tersebut sulit diwujudkan mengingat keterbatasan dalam pengontrolan ekploitasi, serta laju pertumbuhan dari komoditas lobster tersebut yang relatif lambat (Yusnaini et.,all2009).

Sebagai salah satu dasar untuk pengelolaan diperlukan teknik untuk dapat membedakan lobster berdasarkan jenis kelamin, masih membutuhkan suatu pengetahuan tersendiri khususnya pengetahuan mengenai ciri-ciri morfologi baik internal maupun eksternal.

Tujuan tulisan ini untuk menginformasikan teknik identifikasi jenis kelamin lobster secara cepat, berbasis ciri-ciri morfologi eksternal.

\section{POKOK DAN BAHASAN Lokasi dan Waktu}

Pengamatan terhadap jenis kelamin lobster dilakukan pada Juni 2015. Lokasi pengamatan adalah kawasan Pantai Prigi Kabupaten Trenggalek, Jawa Timur.

\section{Bahan}

Sampel lobster yang digunakan berasal dari hasil tangkapan nelayan sebanyak 34 ekor sampel lobster. Sampel lobster ditentukan secara sengaja (purposive sampling) dari jenis Lobster Pasir (Panulirus homarus), yang telah berukuran antara 100-250 gram, untuk memudahkan dalam pengamatan, mengingat lobster yang berukuran kecil (khususnya $>5 \mathrm{gr}$ ) masih mengalami perkembangan fisik dan morfologi seperti belum terbentuknya kaki renang sehingga menyulitkan pengamatan yang sifatnya membedakan.

\section{Metode}

Tahap pengamatan dan identifikasi jenis kelamin meliputi: (1) lobster sampel diukur panjang karapas dan berat kemudian dicatat dalam log book, (2) lobster yang sudah diukur panjang kerapas dan beratnya 
kemudian dilihat jenis kelaminnya, (3) teknik identifikasi jenis kelamin meliputi ciri morfologi eksternal yaitu kaki jalan, kaki renang, dan gonadophore, dan 4) setelah itu lobster sampel di bedah pada bagian karapas chepalatorax untuk mengetahu jenis kelamin melalui ciri morfologi internal (ovarium).

\section{Hasil}

\section{Ciri- ciri Umum Lobster Pasir (Panulirus homarus)}

Tubuh lobster pasir (Panulirus homarus) terdiri dari bagian utama, yaitu bagian kepala yang menyatu dengan dada yang dibungkus dengan karapas yang berduri dan keras, bagian badan terdiri dari daging, punggung dibungkus karapas, dan bagian ekor. Lob- ster pasir mempunyai sembilan pasang kaki, lima pasang kaki jalan, dan empat pasang kaki renang atau lebih dikenal dengan istilah pleopod, lima kaki jalan terletak di sebelah kanan dan lima kaki disebelah kiri. Posisi kaki lobster berada dibawah bagian kerapas dan empat kaki renang yang berada dibawah bagian perut. Kaki renang selain berfungsi untuk berenang juga berfungsi untuk mengendong telur sebelum dilepaskan dialam. Lobster pasir mempunyai punggung berwarna kebiru-biruan, kehijau-hijauan atau cokelat kemerah-merahan, dan terdapat bintik-bintik besar dan kecil berwarna kuning terang. Pada bagian badan terdapat garis kuning, melintang pada bagian sisi belakang segmen abdomen. Selain itu, terdapat bercak-bercak pada bagian kakinya (Gambar 1).

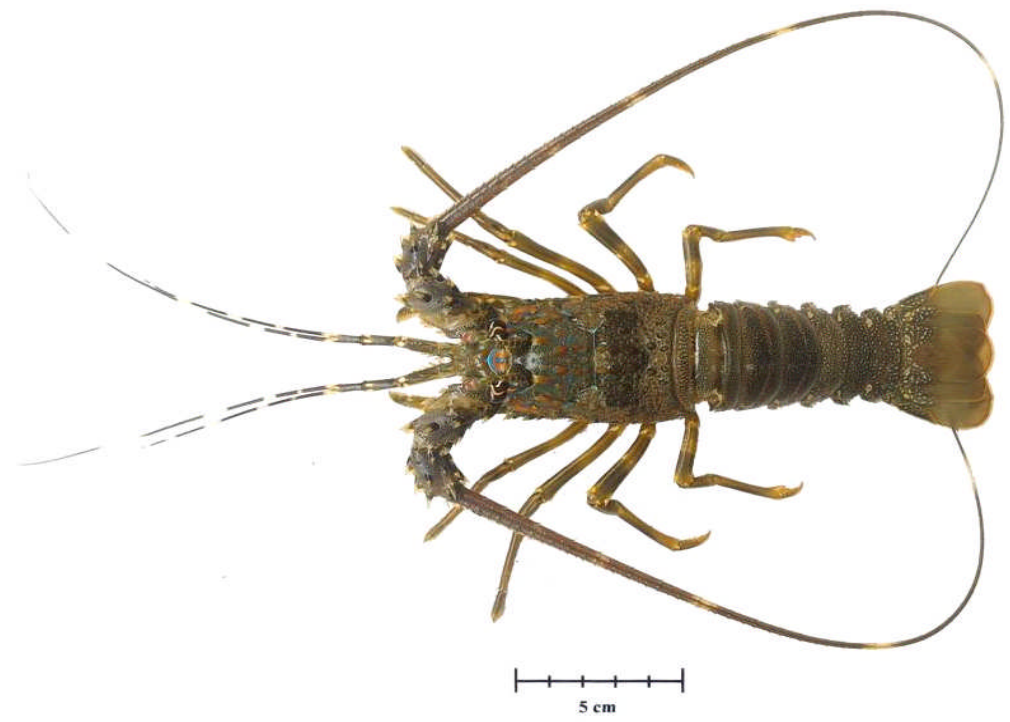

Gambar 1. Lobster Pasir (Panulirus homarus) (Dimas,A.H, 2015).

\section{Ciri-ciri Morfologi Untuk Menentukan Jenis Kelamin}

Mengenali jenis kelamin betina dan jantan dari lobster dapat dilakukan secara morfologis baik yang bersifat eksternal (organ luar) maupun internal (organ dalam), terutama pada lobster dewasa. Ciri- ciri morfologi eksternal meliputi bentuk umum, bentuk kaki jalan, tanda tanda kelamin sekunder (bentuk dan letak gonadophore), serta jumlah lembaran pleopod (kaki renang). Sedangkan morfologi internal dapat dilihat dari bentuk organ reproduksi primer (ovarium). Jenis kelamin lobster mudah untuk diidenfikasi yang berdasarkan bentuk tubuh dan bagian yang ada pada kaki jalan maupun kaki renang sehingga memudahkan untuk penentuan jenis kelamin maupun penyeleksian induk jantan maupun betina. Sedangkan khusus lobster betina lebih mudah dikenal bila mengandung telur. Pada lobster betina dan jantan masing-masing terdapat indung telur dan sepasang kantong sperma. Kantong sperma bermuara pada dasar kaki jalan kelim, dan lubang peneluran bermuara pada dasar kaki jalan yang ketiga. Biasanya ukuran lobster jantan lebih besar dari betinanya, sehingga jantanlah yang paling banyak diincar dan diminati oleh konsumen (chan chu, 1996) dan Chan, (1998).

\section{Lobster Betina}

Ciri ciri morfologi pada lobster betina ditunjukkan oleh adanya tonjolan berwarna putih bening pada kedua pangkal dasar kaki jalan yang ketiga. Tonjolan tersebut merupakan lubang atau ujung dari gonadhopore yakni saluran untuk mengeluarkan telur (Gambar 2 A,B, C). Pada pasangan kaki jalannya yang kelima terdapat capit yang tidak sempurna, yang terjadi karena perubahan ujung kaki yang tumbuh bercabang dua dan ujung ruas kaki berikutnya berubah menjadi semacam duri. Capit ini merupakan capit semu, gunanya untuk merobek kantung sperma yang ada pada waktu pemijahan ditempelkan di antara kakikaki ketiga, keempat dan kelima oleh lobster jantan. 
Sedangkan pada kaki renang lobster betina terdiri atas dua lembar (lembaran berpasangan) berbentuk seperti daun dan berwarna kehijau hijauan. Lembaran sisi luar lebih besar (seperti daun) dari lembaran lainnya (lembaran sisi dalam). Lembaran sisi dalam ini agak bercagak dua, kaku namun lebih tipis dan ramping. Pada lobster juvenile/muda, kedua lembaran kaki renang masih berbentuk daun, tetapi setelah dewasa, lembaran kaki renang bagian dalam mengalami modifikasi terbentuk serabut halus berwarna coklat keputihan, fungsinya untuk menjaga telur-telur tetap menempel sebelum menetas menjadi larva.

\section{Lobster Jantan}

Pada lobster jantan, kaki jalannya semua sama, pada ujungnya hanya terdapat kuku-kuku runcing. Kaki renangnya hanya satu lembar, lembaran kedua sama sekali tidak tumbuh, hanya berupa tonjolan seperti tumpul. Pada pangkal kaki jalan kelima terdapat semacam tonjolan lipatan kulit yaitu liang sperma (gonophore) berbentuk bulat lonjong yang merupakan tempat di mana sperma nantinya dikeluarkan pada waktu pemijahan.

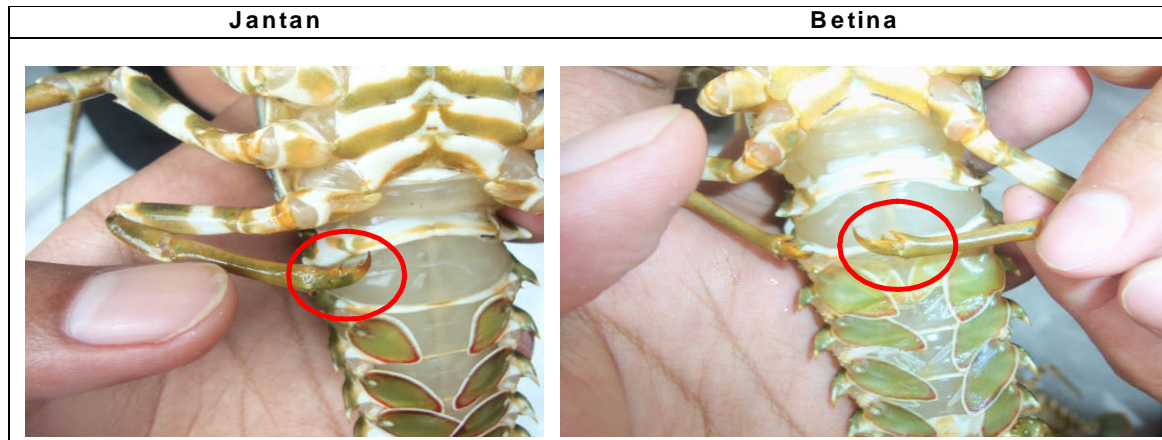

Ruas ujung kaki jalan ke-5

(A) Kaki jalan

runcing (tidak bercabang), tidak berbeda dengan empat dengan

Ujung ruas kaki jalan ke-5 bercabang tiga, berfungsi membawa telur yang sudah fertil ruas ujung kaki jalan lainnya proses penetasan
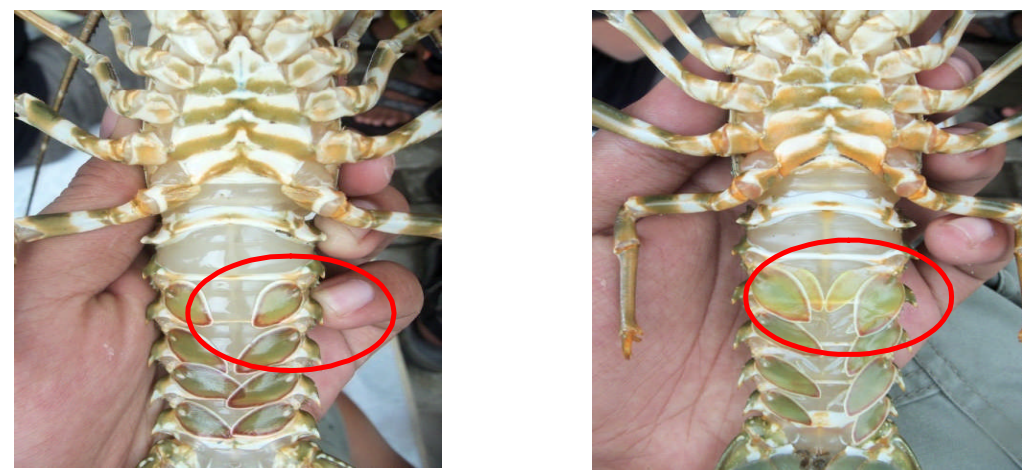

(B) Kaki renang (pleopod)

Sisi dalam kaki renang hanya terdapat 1 lembaran

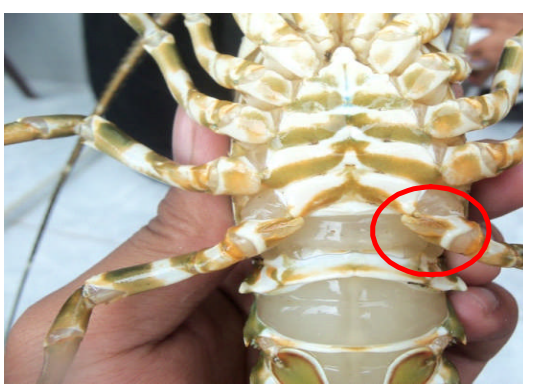

Sisi dalam kaki renang terdapat lembaran berpasangan (2 lembar)

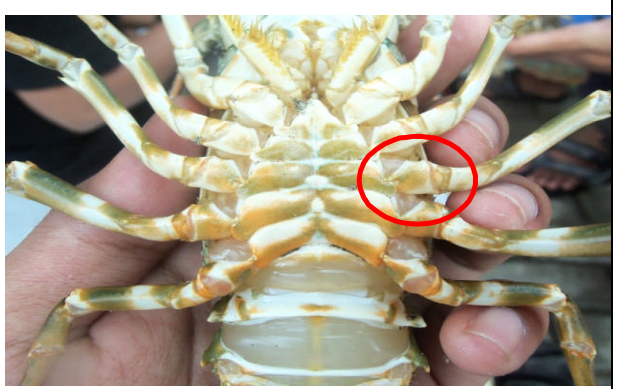

A) alat kelamin (gonophore)

Ada tonjolan gonophore di dasar tangkai jalan kaki ke-5, berhubungan dengan testis
Kedua pangkal dasar kaki jalan ke-3 terdapat tonjolan go $\mathrm{n}$ a d hopore berwarna putih bening

Gambar. 2. A, B, C Ciri-ciri jenis kelamin betina dan jantan Lobster Pasir (Panulirus homarus) 


\section{KESIMPULAN}

Lobster betina dicirikan adanya tonjolan berwarna putih bening (gonadophore ) pada kedua pangkal dasar kaki jalan yang ketiga dan mempunyai kaki renang (pleopod) masing masing dua lembar berpasangan. Lobster jantan mempunyai bentuk tubuh lebih besar dibandingkan dengan lobster betina. Lobster jantan dicirikan letak tonjolan gonophore pada pangkal kaki jalan yang ke lima berbentuk bulat lonjong, ruas ujung kaki jalan ke-5 tidak bercabang, tidak berbeda dengan empat dengan ruas ujung kaki jalan lainnya, dan kaki renang (pleopod) masing masing hanya terdiri dari satu lembar.

\section{PERSANTUAN}

Tulisan ini merupakana bagian dari hasil penelitian "Ecological Assessment untuk Restocking Benih Lobster di Kawasan Konservasi Perairan Indonesia", Anggaran 2015, di Balai Penelitian Pemulihan dan Konservasi Sumberdaya Ikan. Penulis mengucapkan terimakasih kepada Danu Wijaya, S.Pi., MSi dan Dr. Amula Nurfiarini, S.P., M.Si selaku penanggung jawab lapangan yang memberikan sebagian data sehingga penulis bisa menyelesaikan makalah ini.

\section{DAFTAR PUSTAKA}

Anonimus. (2016). Jenis-jenis lobster laut di Indonesia. https://www.google.co.id/ search?q=jenis-jenis+lobster+air+laut. diakses pada tanggal 05 Nopember 2016.

BP2KSI (Balai Penelitian Pemulihan dan Konservasi Sumber Daya Ikan). (2015). Ecological assessment untuk restocking benih lobster di kawasan konservasi Perairan Indonesia. Laporan Teknis Penelitian (Tidak dipublikasikan). Balai Penelitian Pemulihan dan Konservasi Sumberdaya Ikan.

Chan, T. Y \& Chu, K.H. (1996). (Decapoda, Palinuridae). Crustaceana. 74, 123-127.

Chan, T. Y. (1998). Lobster. In Carpenter K. E, Niem, V.H (eds). FAO species Identification Guide for Fishery Puposes. The living Marine Resources of the Western Central Pasific. FAO. Rome. Vol. 2, 687-1396.

Junaidi M., Cokrowati N., Abidin, Z. (2010). Aspek reproduksi lobster (Panulirus sp.) di Teluk Ekas, pulau Lombok. Jurnal Kelautan 3(1),29-36.

Yusnaini, M.N.. Nisa, M.Djawad., \& Trijuno. D.D. (2009). Ciri morfologi jenis kelamin dan kedewasaan lobster mutiara (Panulirus ornatus) Sex Morfologycal Characteristcs And Maturity Of The Ornated Lobster Panulirus ornatus. Jurnal Torani (Jurnal ilmu Kelautan dan Perikanan. Vol 19 (3) Desember 2009: 166-174 